\title{
Assessment of tensile behaviour of an Al-Mg alloy composite reinforced with NiAl and oxidized NiAl powder particles helped by nano indentation
}

\author{
H. A. Pour ${ }^{\mathrm{a}, \mathrm{b}}$, M. Lieblich ${ }^{\mathrm{a}}$, A. J. López ${ }^{\mathrm{c}}$, J. Rams ${ }^{\mathrm{c}}$, M. T. Salehi ${ }^{\mathrm{b}}$, S. G. Shabestari ${ }^{\mathrm{b}}$,
}

${ }^{a}$ Department of Physic al Metallurgy, National Centre for Metallurgic al Research, CENIM-CSIC, Avda. Gregorio del Amo 8, 28040 Madrid, Spain.

${ }^{\mathrm{b}}$ Department of Metallurgy and Materials Engineering, Iran University of Science and Technology (IUST), Narmak, 16844 Tehran, Iran

\author{
${ }^{c}$ Department of Materials Science and Engineering, Escuela Superior de Ciencias Experimentales y \\ Tecnología, Universidad Rey Juan Carlos, 28933 Móstoles, Madrid, Spain.
}

\begin{abstract}
AA5056 matrix composites have been reinforced with as-received and oxidized NiAl partic les and their nanohardness inves tigated as a function of distance to reinforcement. Results ind icate that a non-heat treatable aluminium matrix, as is the pres ent case, does not require that the intermetallic particles are surrounding by a protective $\mathrm{Al}_{2} \mathrm{O}_{3}$ layer to avoid reactions at matrix-reinforcement interfaces. On the other hand, the quality of the matrix-reinforcement bonding has been quantified by the reinforcement Influence Distance, defined as the distance from the particle at which the nanohardness of the matrix drops to its asymptotic value.
\end{abstract}

Keywords: A. Metal matrix composites (MMCs); A. Intermetallic s; B. Mechanical properties; E. Powder process ing. 


\section{Introduction}

Aluminium matrix composites (AMCs) have in general higher specific strength, stiffness and heat resistance than the unreinforced matrix alloy. AMCs reinforced with ceramic particles have already found several applications. However, they suffer from some drawbacks due to high abrasiveness and brittleness of ceramics. In the last years, intermetallic particles have emerged as possible substitutes for ceramic reinforcements in aluminium alloys [1-7]. Among the intermetallics, NiAl appears as a promising candidate as it combines low density and a high Young modulus (at stoichiometric composition and room temperature, $5.86 \mathrm{~g} / \mathrm{cm}^{3}$ and $294 \mathrm{GPa}$, respectively [8]) and especially in comparison with $\mathrm{Ni}_{3} \mathrm{Al}$.

Powder metallurgy (PM) is the most suitable method for processing these intermetallic reinforced composites because of its capacity to prevent reactions between matrix and reinforcement $[1,2]$. However, deleterious reaction products at intermetallic/matrix interfaces may still form during solid solution treatments $[3,4,5]$ giving rise to brittle interphases and modifications in matrix composition, which result in the worsening of mechanical properties. In a previous work, NiAl particles were submitted to a pre-oxidation treatment to form a protective alumina layer that delayed the nucleation and growth of $\mathrm{Al}_{3} \mathrm{Ni}$ and $\mathrm{Al}_{3} \mathrm{Ni}_{2}$ phases at $\mathrm{NiAl} / \mathrm{Al}$ interfaces [6].

Oxidized particles also presented quite a sound bond to the matrix. These conditions proved to be very suitable for age hardening $\mathrm{Al}$ alloy matrices, which should be submitted to a solution treatment after processing. However, when the matrix is a work hardening alloy, as in the present investigation, the alumina protective layer may not be necessary. 
In this study, the work hardening AA5056 aluminium alloy has been reinforced with $15 \%$ volume of as-received and oxidized NiAl particles through a PM route. Both composites have been submitted to tensile tests and their microstructure investigated. The quality of particle-matrix bonding has been quantified by analysing the matrix nanohardness obtained as a function of the distance to the reinforcement.

\section{Experimental procedure}

Two composites have been proces sed by PM using a work hardening AA5056 alloy matrix (composition in wt. \%: Mg 5.01, Si 0.02, Cu 0.03, Mn 0.13, Cr 0.09, Fe 0.02, balanced $\mathrm{Al}$; powder particle size: $<75 \mu \mathrm{m}$ ) and $15 \mathrm{vol}$. $\%$ of NiAl particles $<25 \mu \mathrm{m}$ as reinforc ement. In one material (5056/NiAl), the NiAl particles were introduced asreceived, whereas in the other (5056/NiAlox), they were submitted to an oxidizing heat treatment of 3 hours at $750^{\circ} \mathrm{C}$ in air prior to being mixed with the alloy powder.

Composite powders were wet mixed in a cyclohexan solution with a rotating magnet for 5 hours and then dried at $95^{\circ} \mathrm{C}$, canned, kept 15 minutes at $450^{\circ} \mathrm{C}$ and immediately hot extruded with an extrusion ratio of $28: 1$ and a ram speed of $0.4 \mathrm{~mm} / \mathrm{s}$. The final bar was $7 \mathrm{~mm}$ in diameter.

Cylindrical tensile specimens of $3 \mathrm{~mm}$ diameter and $20 \mathrm{~mm}$ gauge length were machined from the extruded bars while maintaining the tensile axis parallel to the extrusion direction. These composites, to gether with the unreinforced matrix (5056)

processed by the same route, were submitted to tensile tests at room temperature at a strain rate of $5 \times 10^{-4} \mathrm{~s}^{-1}$. Polished longitudinal sections were observed by optical 
microscopy and scanning electron microscopy (FEG-SEM). Vickers hardn ess was determined at $1 \mathrm{~kg}$ load.

Nanohardness was measured with an atomic force microscope equipped with a nanoindenter test system from Hysitron. A cube-corner tip was used applying loads in the 700 to $7000 \mu \mathrm{N}$ range. Cube-corner tips are more acute than Berkovich ones, so they provide deeper penetrations for identical loads, giving rise to larger plastic deformation of the tested matrix alloy.

\section{Results and discussion}

The tensile and hardness properties of the three materials are collected in Table 1. As expected from previous results on $\mathrm{Al} / \mathrm{NiAlox}[6]$, the oxidation treatment given to the NiAl particles was effective, as yield stress of the 5056/NiAlox composite was higher than that of the monolith alloy. What is more interesting to point out is the fact that the 5056 alloy reinforced with unoxidized NiAl particles presented even higher YS, UTS and Hv than 5056/NiAlox, although elongation to failure was lower. This better behaviour should arise from better matrix/reinforcement bonding of NiAl to the matrix, that helps a more efficient load transference. This bonding cannot be only mechanical because unoxidized particles have a much smoother surface than oxidized ones [6]. On

the other hand, as is shown in the micrograph of Figure 1, two narrow reaction layers of $\mathrm{Al}_{3} \mathrm{Ni}$ and $\mathrm{Al}_{3} \mathrm{Ni}_{2}$ interphases, developed between matrix and $\mathrm{NiAl}$ particles already during the extrusion process. This is the opposite to what occurred in similar $\mathrm{Al} / \mathrm{NiAl}$ [6], 5056/Ni $3 \mathrm{Al}[4]$ and $\mathrm{Al} / \mathrm{Ni}_{3} \mathrm{Al}$ [7] composites where no reaction phases appeared during processing, and suggests that $\mathrm{NiAl}$ is more reactive than $\mathrm{Ni}_{3} \mathrm{Al}$ and/or the $\mathrm{Mg}$ of 
the matrix makes it more reactive. Also striking is the fact that in this system the reaction phases improve bonding instead of worsening it as happened after a conventional solution treatment [5] and indicates that limited matrix/reinforcement interactions are an advantage for the mechanical properties of this composite, as occurs in other Al matrix composites, see for example $[9,10]$. The new interphases also have the effect of increasing volume locally [5], promoting compressive stresses in the matrix around the intermetallic particles $[7,11]$. This again may contribute to the higher tensile strength of this NiAl reinforced composite by work hardening its 5056 matrix.

A further aspect that distinguishes the studied composites is their elongation to failure, which is larger for 5056/NiAlox, Table 1. As suggested by several authors [12], fracture process in particle reinforced alloys has the same sequence as fracture in dispersion hardening materials; void nucleation originated at particle cracks or particlematrix interface, void growth, void coalescence and matrix failure. In 5056/NiAlox, Figure 2a, voids are generated primarily by decohesion of the matrix-particle in terface and from this it follows that the bonding between the matrix and the $\mathrm{Al}_{2} \mathrm{O}_{3}$ layer of the NiAlox particles is not very strong. The high ductility of this material is due to the matrix flowing around the detached particles, as is manifested by the very large voids that can be seen around them. On the other hand, in 5056/NiAl voids are smaller and it is evident that particle fracture is the major failure mechanism, Figure $2 \mathrm{~b}$. Particle fracture indicates that the load transfer is much more efficient at the 5056-NiAl interface than at the 5056-NiAlox interface and that local stresses become higher than their fracture stress $[13,14]$. In Figure 3, the percentages of debonded and fractured particles in the two composites regarding the number of particles are shown as a function of the distance to the fracture surface. From this graph it is evident that the 
number of damaged particles is higher for 5056/AlNiox. In this material, as plastic deformation increases more and more particles become debonded liberating the matrix that is then able to flow, so that final fracture occurs in a ductile manner. However, in 5056/NiAl a smaller amount of NiAl become damaged and, when NiAl particles break, the constraint of the matrix to flow plastically is removed suddenly and final failure occurs in a more brittle manner.

To investigate to what extent the matrix is affected by the reinforcing particles and to characterise the particle-reinforcement interfacial region, nanoindentation was performed at $700 \mu \mathrm{N}$ load, which resulted in indentation depths of almost $200 \mathrm{~nm}$. Figure 4 presents hardness and elastic modulus (inset) plotted as a function of distance to the closest particle. The first thing that can be seen in this figure is that there is a wide dispersion of results, i.e. indentations that are far from any visible particle but show a high nanohardness value. This indicates that they are affected by other particles beneath the surface. Bearing this in mind, it has been considered that only the lowest nanohardness values of each composite corresponded to the matrix that is not influenced by any particle apart from visible ones. These lowest values were fitted to the exponential curves drawn on the graph. In this way, the nanohardness of the matrices far from any particle can be assimilated to the asymptote of the curves. It can be seen that the matrix in the $5056 / \mathrm{NiAlox}$ composite is softer, $1.2 \mathrm{GPa}$, than that of 5056/NiAl, 1.4 GPa. Another result derived from the curves is the existence of a reinforc ement influence distance (ID), that can be defined as the distance from the particle at which the nanohardness is only $5 \%$ above that of its asymp totic value at the matrix. This ID is equal to $2.1 \mu \mathrm{m}$ for the NiAlox particles, clearly shorter than the 6.9 $\mu \mathrm{m}$ of the unoxidized NiAl particles. This tendency may also be observed in the elastic 
modulus, but the higher dispersion of results makes it difficult to evaluate. The fact that the ID is larger for NiAl particles is another sign of their more significant influence on its matrix.

As it has already been stated, the dispersion of nanohardness results is very wide for both composites, but here again there is a difference between them because dispersion is not as large for the $5056 / \mathrm{NiAlox}(60 \%$ of results) as for the $5056 / \mathrm{NiAl}$ composite (almost $80 \%$ ). This indicates once again that the matrix of the latter is more affected by the reinforcing particles, which is due to their larger ID.

To asses the brittle or ductile nature of the interfacial regions, indentations with higher loads (3000 and $7000 \mu \mathrm{N})$ were performed in the vicinity of the particles, i.e. at distances shorter than the ID, in order to increase the plastic deformation and show more clearly the plastification phenomena and the particle matrix interaction [15]. Indenting in the NiAlox surroundings, Figure 5a, shows that the matrix behaves in a ductile way becau se piling-up takes place by the same amount in the three faces of the indentation print. Moreover, in the face oriented towards the reinforcing NiAlox particle the matrix even spreads over the particle. However, in the case of the material fabricated with unoxidized NiAl particles, piling-up does not appear at the indentation face oriented towards the reinforcement, Figure $5 \mathrm{~b}$. The depth profiles across the indentation prints, Figure 5c, illustrate these situations of piling-up and sinking-in, characteristic of ductile and brittle behaviour respectively [16]. The sinking-in indicates a strong interaction between the unoxidized NiAl particles and the 5056 matrix inside the influence region, that prevents the matrix flowing as it does when the reinforcing particles are oxidized. 


\section{Conclusions}

The AA5056 matrix composite reinforced with unoxidized NiAl particles presents higher YS, UTS and Vickers hardness than the same matrix reinforced with oxidized NiAl and than the monolith AA5056 alloy.

This indicates that in non-heat treatable aluminium alloys, it is not necessary to create a protective coating on the intermetallic reinforcing particles in order to avoid deleterious reaction at matrix-reinforcement interfaces.

The better mechanical behaviour of the $5056 / \mathrm{NiAl}$ composite is due to a better bonding of the reinforcement, which is also shown by more brittle behaviour.

The quality of the bonding has been quantified by the reinforcement influence distance, defined as the distance from the particle at which the nanohardness of the matrix around it drops to its asymptotic value.

The ID is equal to $6.9 \mu \mathrm{m}$ for the unoxidized NiAl particles, clearly longer than the $2.1 \mu \mathrm{m}$ of the NiAlox particles. The much larger influence region of the unoxidized reinforcement explains the higher macrohardness of th is composite and its limited ductility.

\section{Acknowledgements}

Financial support of Spanish Ministry of Education and Science, projects CICYT MAT2003-00722, MAT2003-04931-C02-02 and MAT2006-01251, is greatly acknowledged. H.A.P. acknowledges the Iranian Ministry of Science, Research and Technology for a scholarship. 


\section{References}

[1] Omura H, Miyoshi T, Takahashi Y, Conley CG and Yodogawa M, in: Y.-M. Kim and W. M. Griffith editors. Dispersion Strengthened Aluminum Alloys. The Minerals, Metals, and Materials Society, Warrendale, PA, 1988, p. 421-435.

[2] González-Carrasco JL, García-Cano F, Caruana G and Lieblich M, Mater. Sci. Eng. 1994;183A:L5-L8.

[3] Lieblich M, González-Carrasco JL and Caruana G, Intermetallics 1997;5:515-524.

[4] Torres B, Wang Y, Lieblich M, Ibáñez J, Rainforth WM and Jones H, Z. Metallkde $2001 ; 92: 604-609$.

[5] Torres B, Lieblich M, Ibáñez J and García-Escorial A, Scripta Mater. 2002;47:45-49.

[6] Pour HA, Lieblich M, Shabestari SG andSalehi MT, Scripta Mater. 2005;53:977-982.

[7] Lieblich M, González-Carrasco JL, García-Cano F, J. Mater. Sci. Letters 1999;18:905-908.

[8] Liu CT, Stiegler JO, and Froes FH (Sam), in: ASM Handbook, Vol. 2, 10th Ed., ASM International,1990, p. 913.

[9] Tham LM, Gupta M and Cheng L, Acta Mater. 2001;49:3243-3253.

[10] Feest EA, Composites 1994;25:75-86.

[11] Klinger L and Levin L, Scripta Metall. Mater. 1994;31:769-773.

[12] Derby B and Mummery PM, Fundamentals of Metal Matrix Composites. Suresh S, Mortensen A and Needleman A editors. Butterworth-Heineman, London,1993, p. 251.

[13] Lloyd DJ, Acta Metall. Mater. 1991;39;59-71.

[14] Zhong WM, L'Espérance G and Suéry M, Mater. Sci. Eng. 1996;A214:104-114.

[15] Campo M, Ureña A, Rams J, Scripta Mater. 2005;52:977-982.

[16] Xu ZH, Agren J, Philos. Mag. 2004;84:2367-2380. 


\section{FIGURE CAPTIONS}

Fig. 1. Polished cross section of 5056/NiAl showing interfacial reactions.

Fig. 2. Lon gitud inal cross sections close to the fracture surface in (a) $5056 / \mathrm{NiAlox}$ and (b) $5056 / \mathrm{NiAl}$.

Fig. 3. Fraction of particles that are debonded (in 5056/NiAlox) or fractured (in $5056 / \mathrm{NiAl})$ as a function of distance to the fracture surface of the tensile specimens.

Fig. 4. Nanohardness and elastic modulus (inset) as a function of distance to the nearest reinforcing particle of (a) 5056/NiAlox and (b) 5056/NiAl.

Fig. 5. High load indentation prints in (a) 5056/NiAlox and (b) 5056/NiAl. Part (c) are the depth profiles along the lines indicated in the prints in (a) and (b).

\section{TABLE}

Table 1. Yield stress (YS), Ultimate tensile strength (UTS), elongation to failure (El) and Vickers hardness $(\mathrm{Hv})$.

\begin{tabular}{lcccc} 
Material & YS, MPa & UTS, MPa & El, \% & Hv, GPa \\
\hline 5056 & 199 & 347 & 16 & 0.86 \\
\hline $5056 /$ NiAlox & 210 & 322 & 8 & 1.00 \\
\hline $5056 / \mathrm{NiAl}$ & 256 & 331 & 3 & 1.14 \\
\hline
\end{tabular}


Click here to download high resolution image

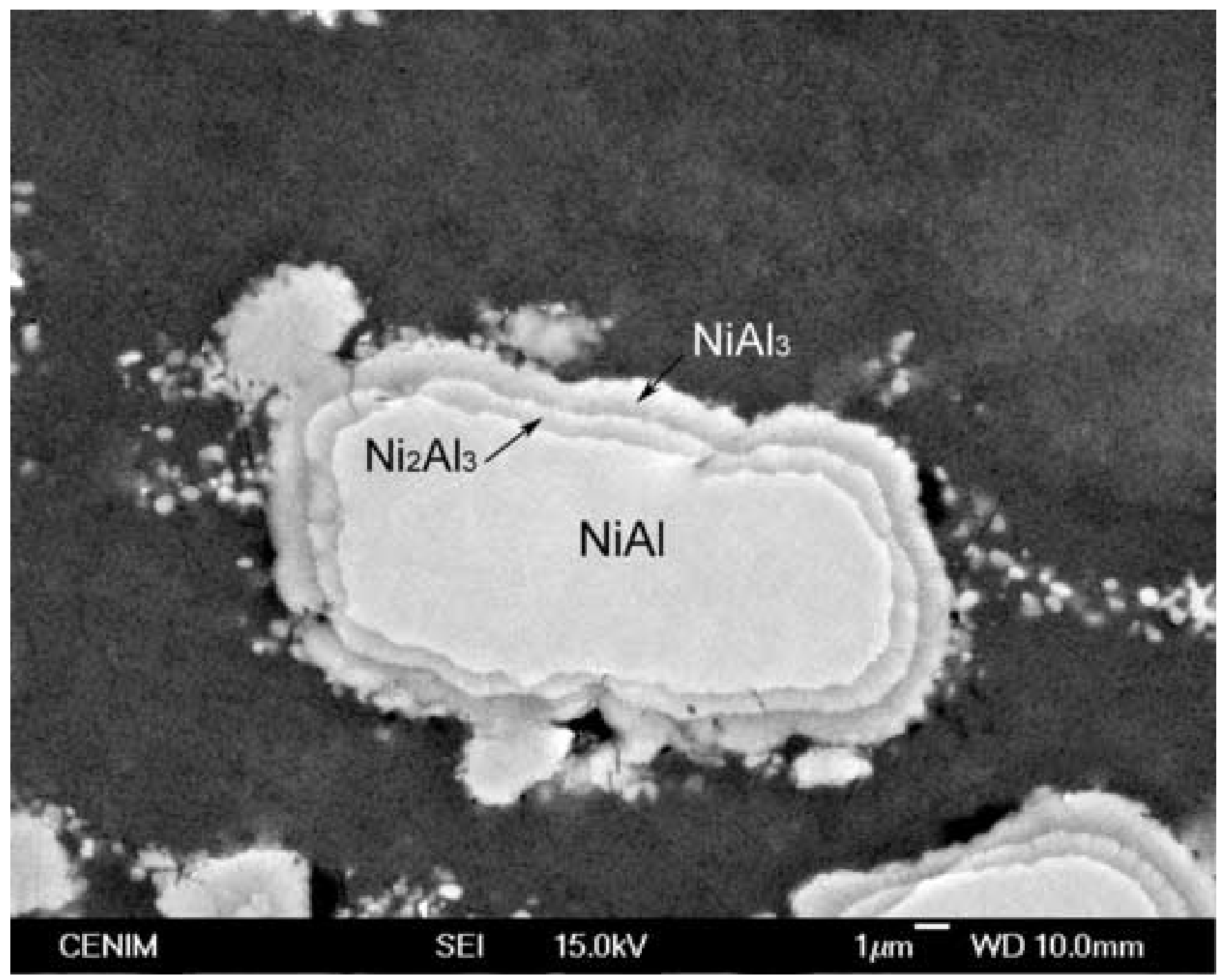


Figure $2 \mathrm{a}$
Click here to download high resolution image

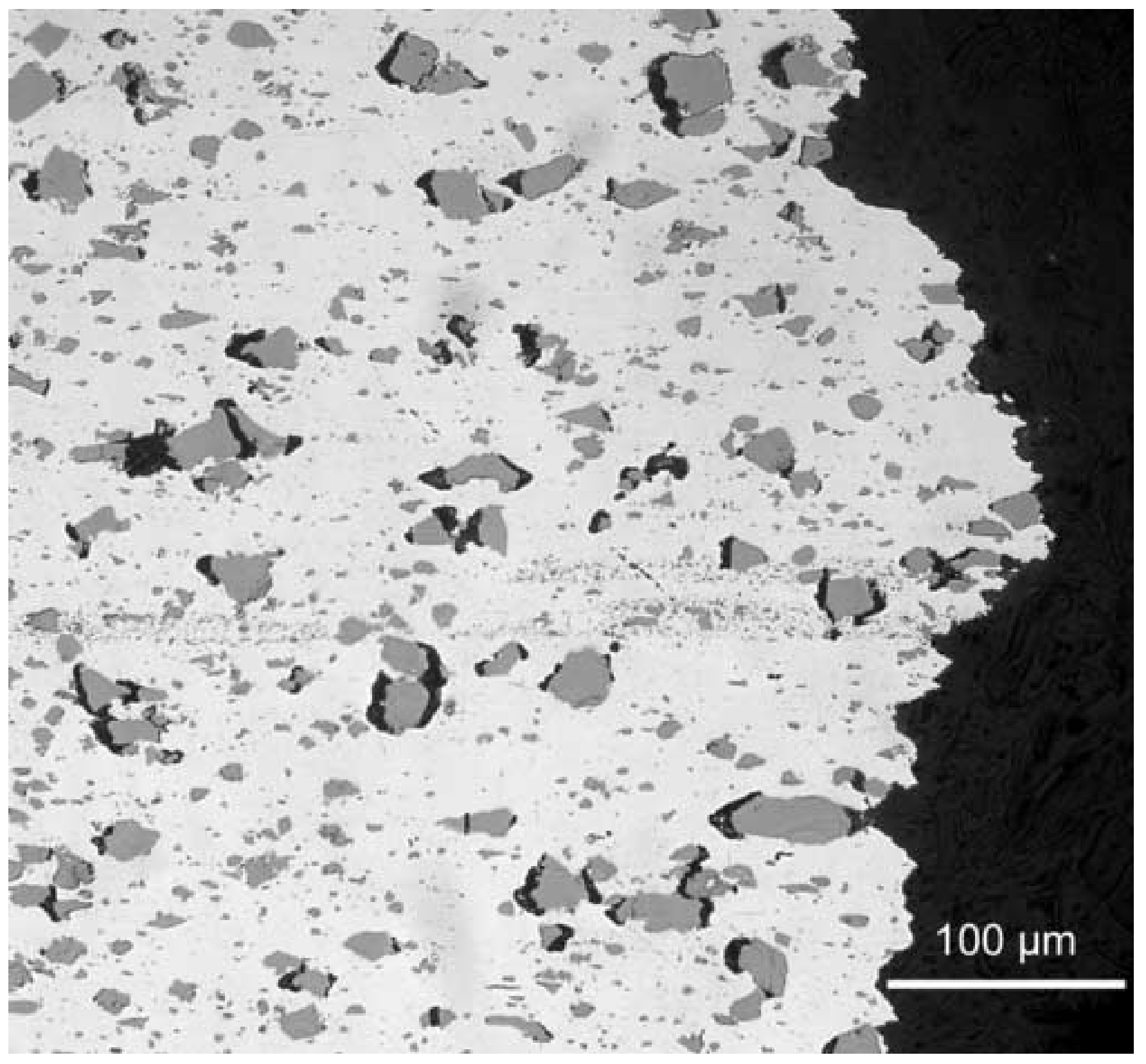


Figure $2 b$
Click here to download high resolution image

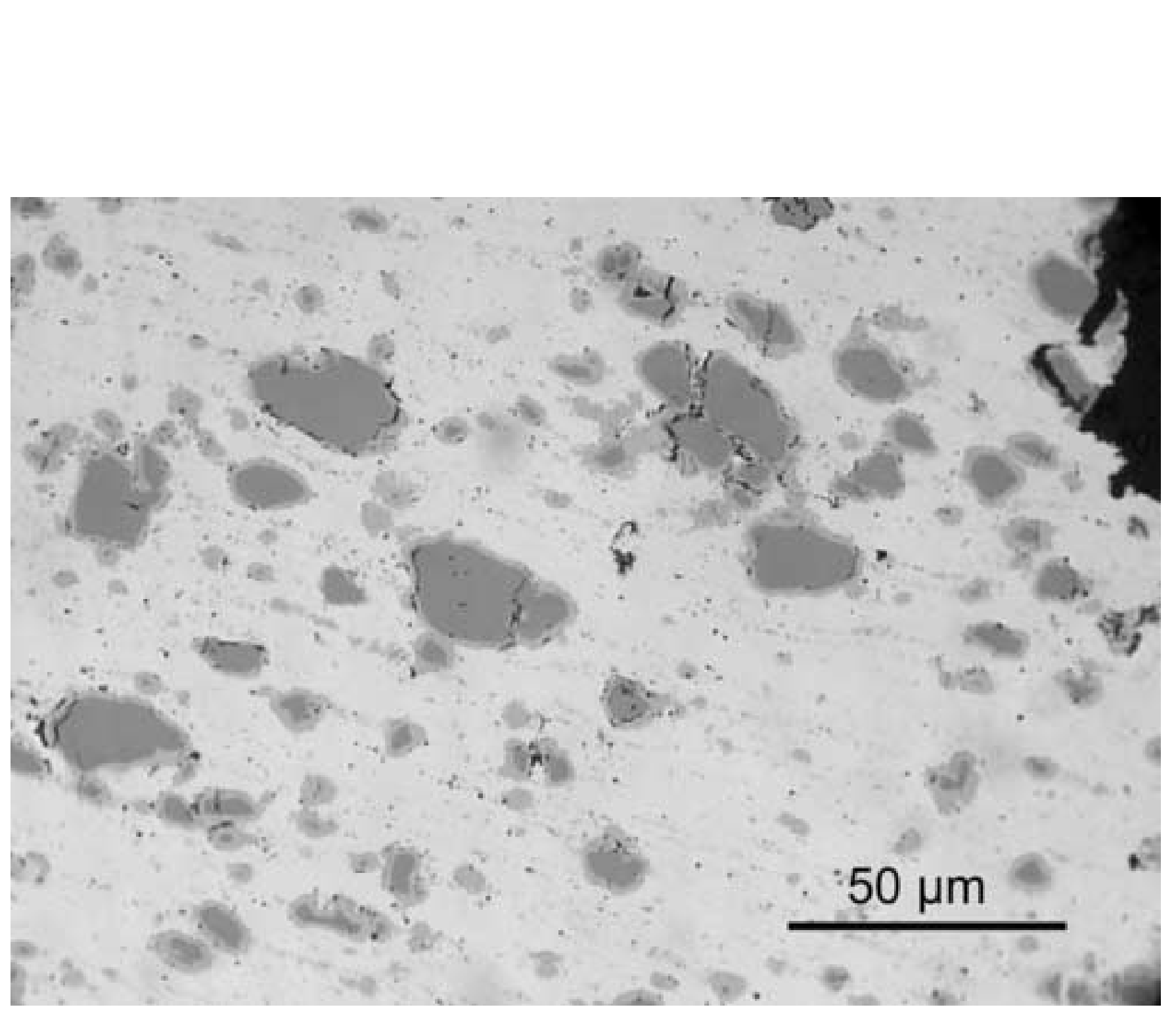

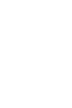

(1)


Figure 3
Click here to download high resolution image

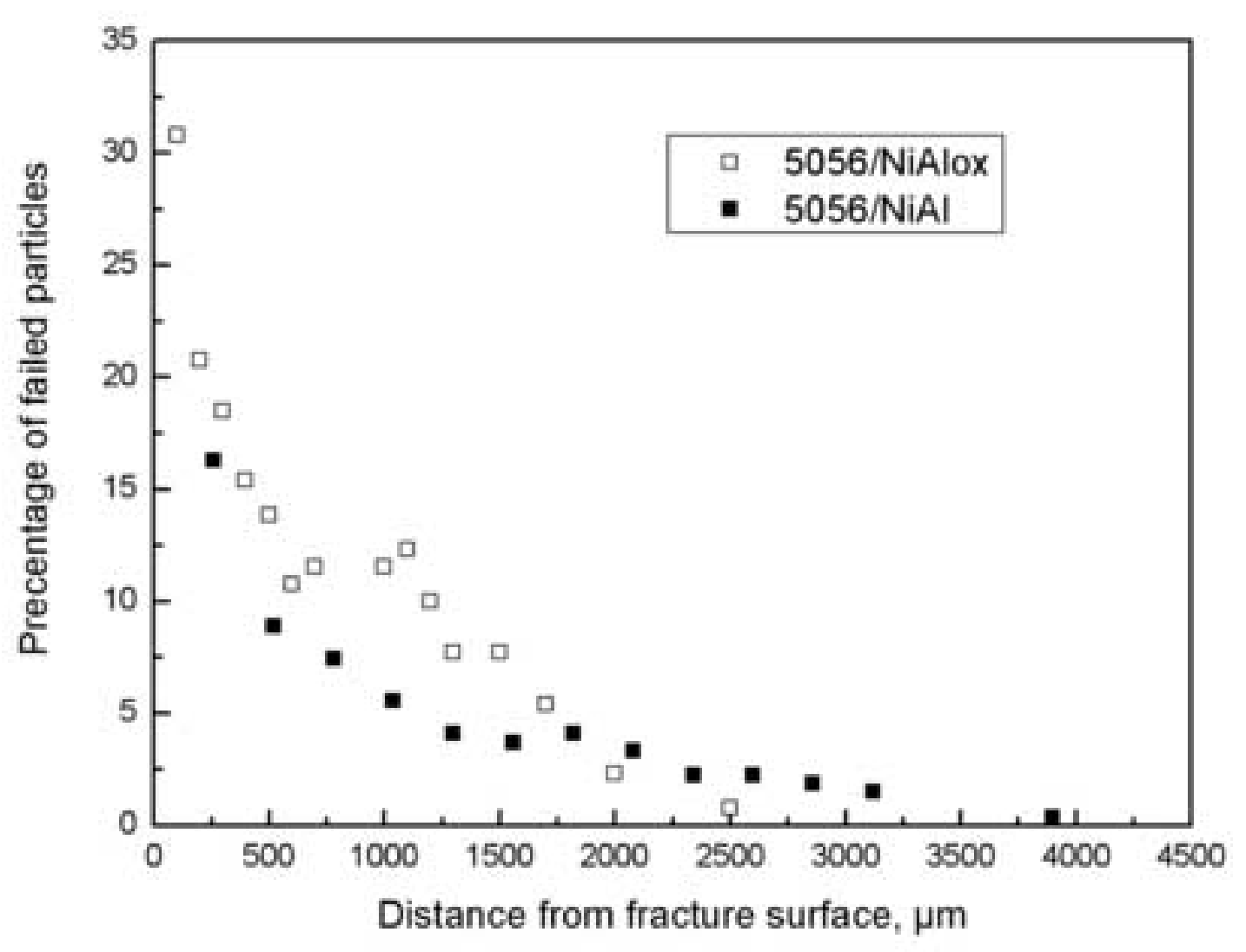


Figure 4
Click here to download high resolution image

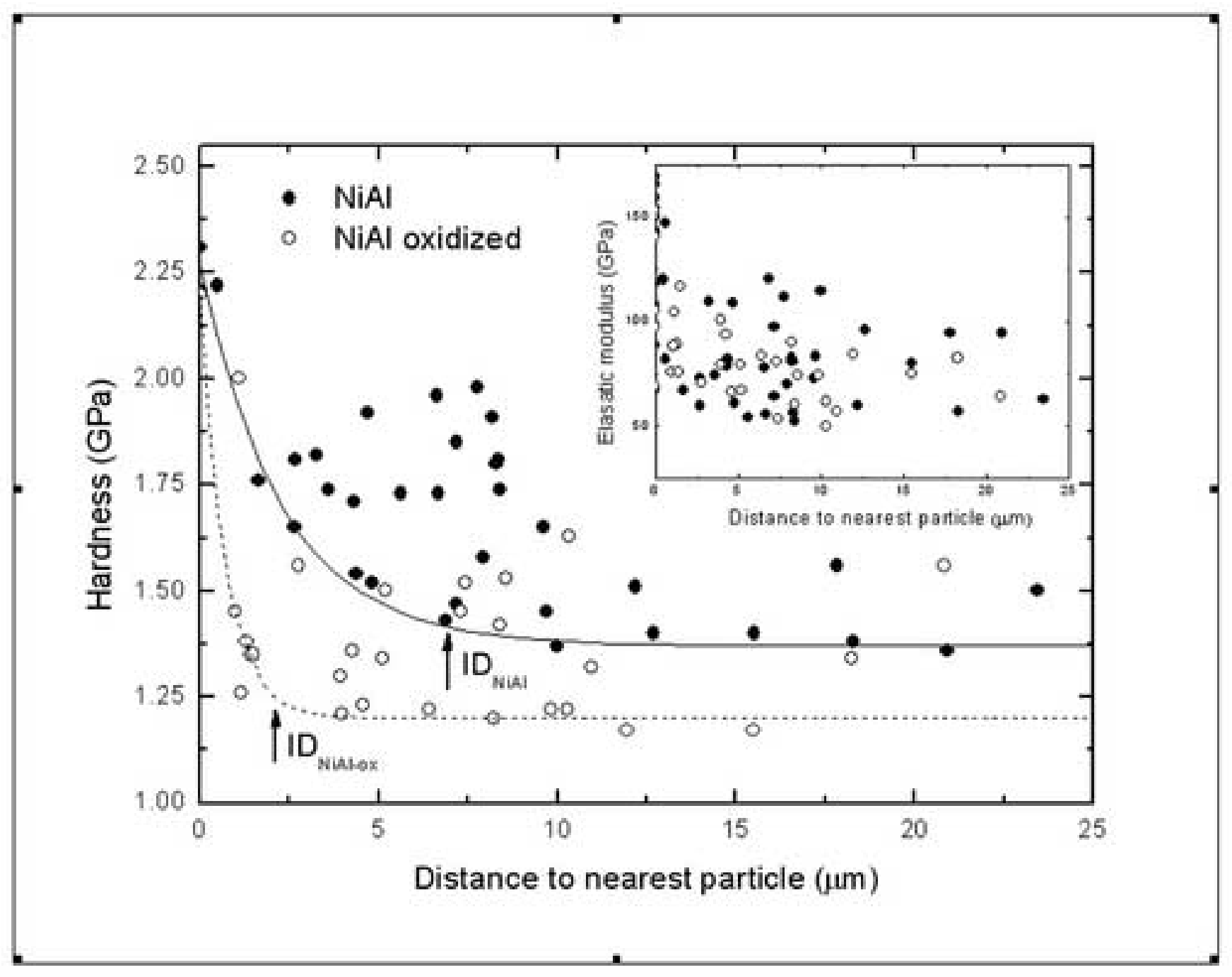




\section{Figure 5a}

Click here to download high resolution image

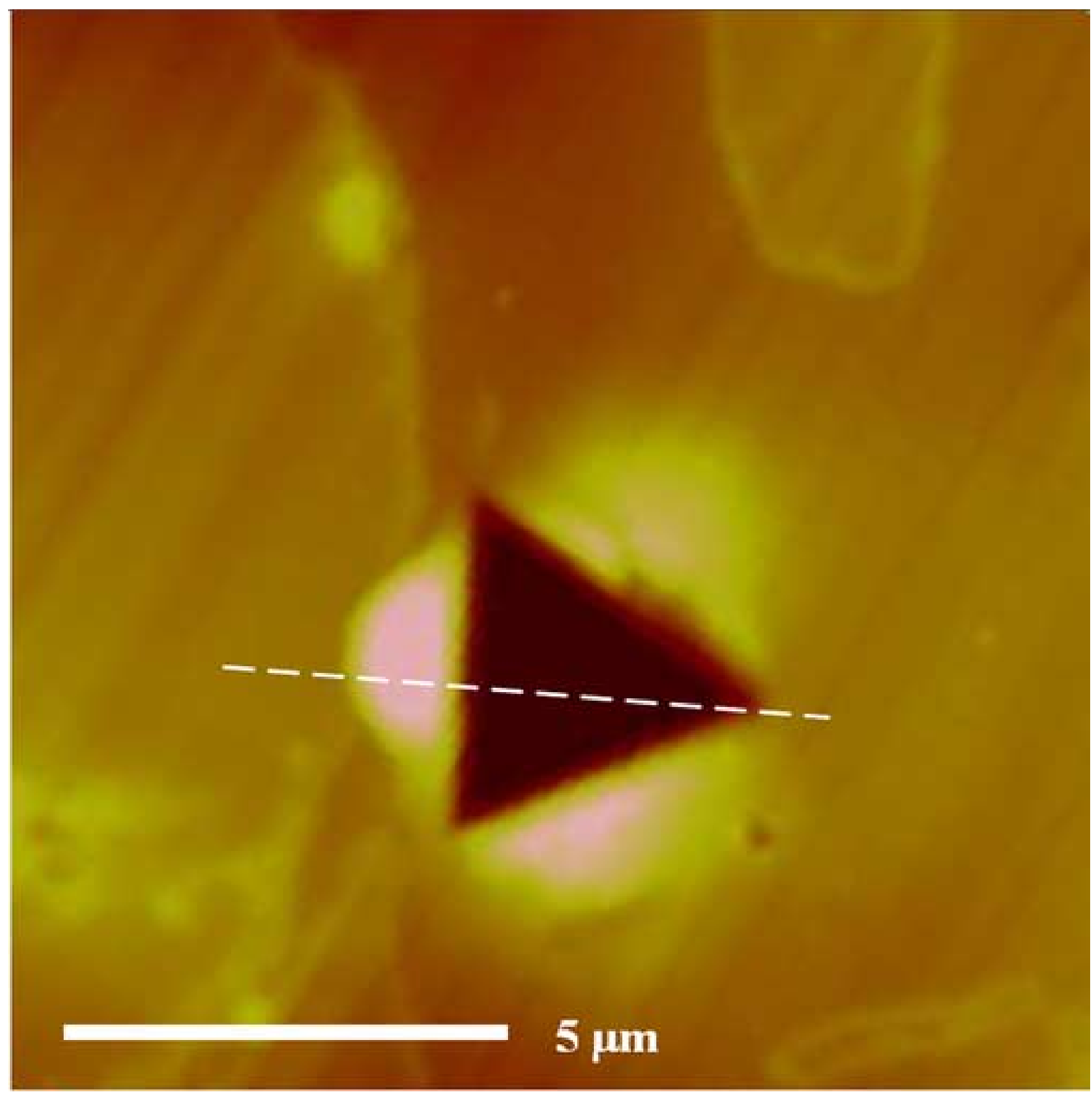




\section{Figure 5b}

Click here to download high resolution image

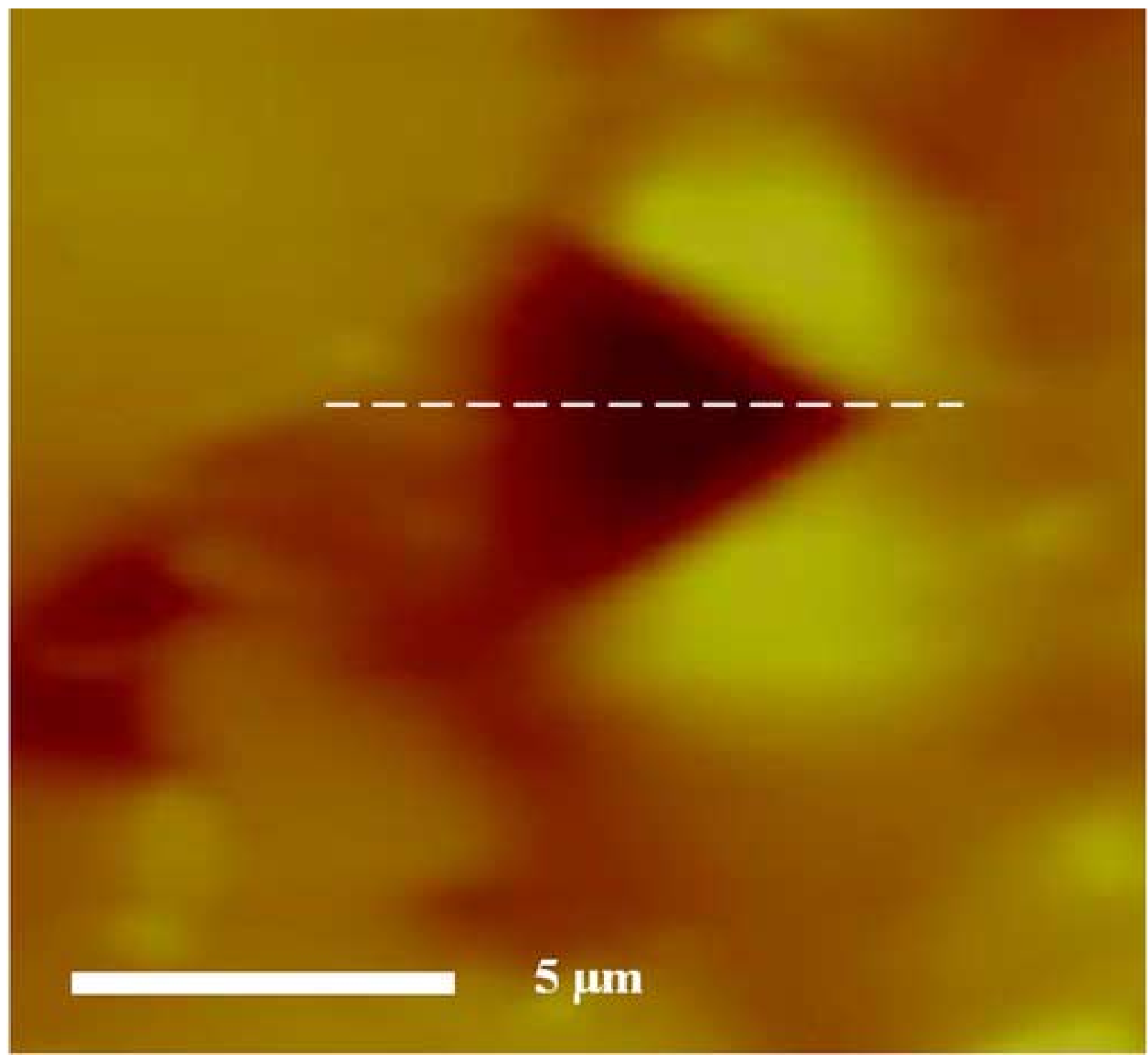


Figure $5 c$
Click here to download high resolution image

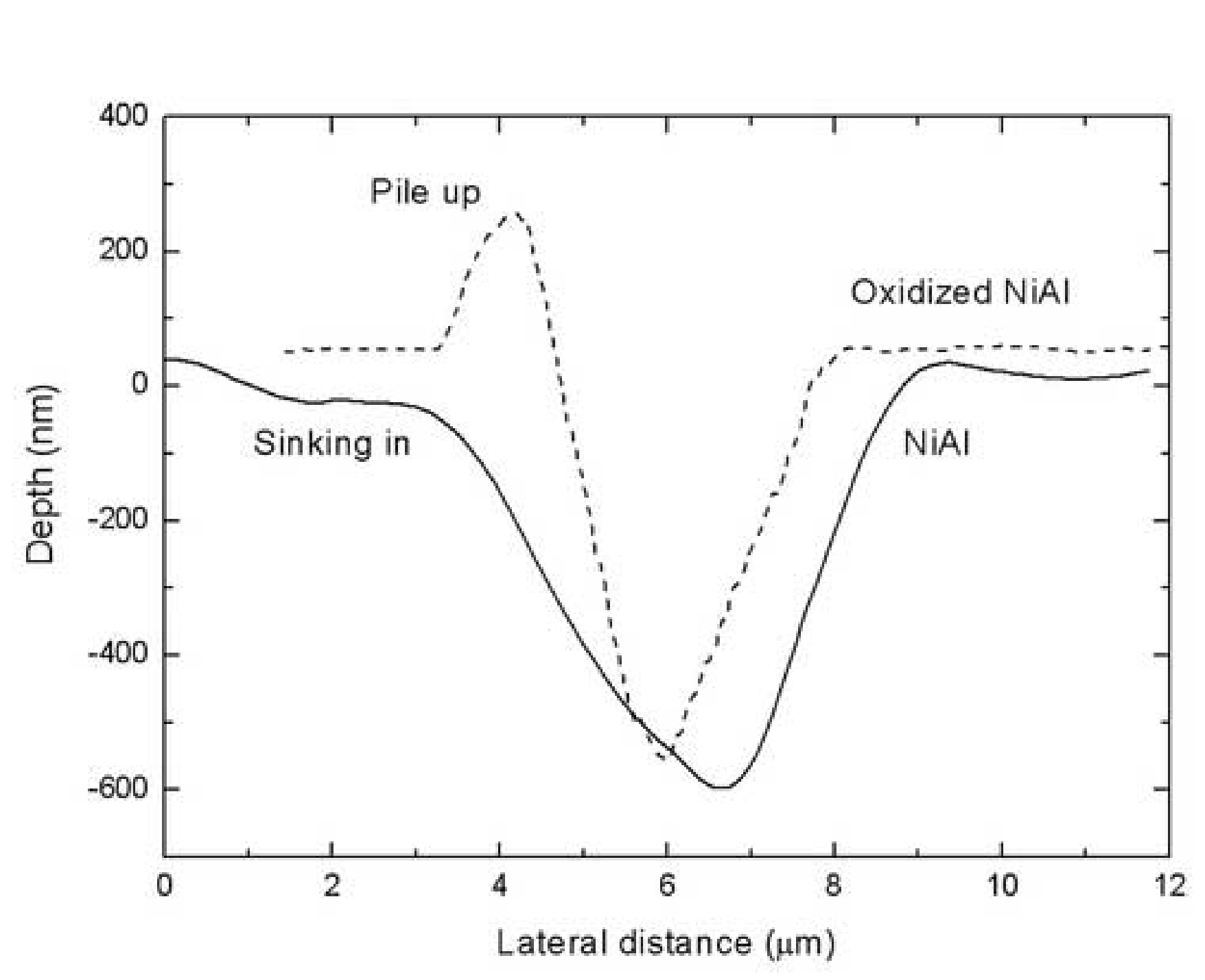

Click here to download high resolution image

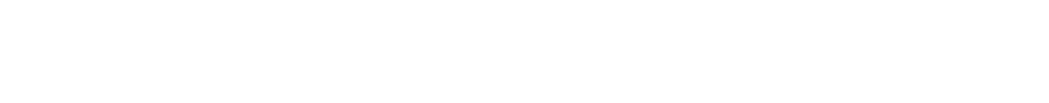

